\title{
Harambee! 2.0: The Impact of HIV-Related and Intersectional Stigmas on HIV Testing Behaviors Among African Immigrant Communities in Seattle, Washington
}

\author{
Nahom A. Daniel ${ }^{1}$. Shukri A. Hassan ${ }^{2} \cdot$ Farah Mohamed $^{2,3} \cdot$ Najma Sheikh $^{4} \cdot$ Guiomar Basualdo $^{5} \cdot$ Rahel Schwartz $^{6,7}$. \\ Beyene Tewelde Gebreselassie $^{8} \cdot$ Yikealo K. Beyene $^{8} \cdot$ Luwam Gabreselassie $^{8} \cdot$ Kifleyesus Bayru $^{8} \cdot$ Bethel Tadesse $^{6}$. \\ Hirut Amsalu Libneh ${ }^{6} \cdot$ Mohamed Shidane $^{3}$. Sophia Benalfew ${ }^{6} \cdot$ Ahmed Ali $^{3,4}$. Deepa Rao ${ }^{4}$. Roxanne P. Kerani ${ }^{2}$. \\ Rena C. Patel ${ }^{2,4}$ (1)
}

Accepted: 18 July 2021 / Published online: 9 August 2021

(c) The Author(s), under exclusive licence to Springer Science+Business Media, LLC, part of Springer Nature 2021

\begin{abstract}
African immigrants are disproportionately affected by HIV compared to U.S.-born individuals, and early HIV testing is the key challenge in ending the HIV epidemic in these communities. HIV-related stigma appears to be the most significant barrier to testing for HIV among African communities in King County, WA. In this formative study, we conducted thirty key informant interviews and five focus group discussions ( $\mathrm{n}=$ total 72 participants) with Ethiopian, Somali, and Eritrean people living with HIV, health professionals, religious and other community leaders, and lay community members in King County to better understand HIV-related and intersectional stigmas' impact on HIV testing behaviors. We used inductive coding and thematic analysis. Participants from all communities reported similar themes for HIV-related and intersectional stigmas' influences on HIV testing behaviors. Misconceptions or poor messaging, e.g., regarding treatability of HIV, as well as normative or religious/moral beliefs around pre/extramarital sex contributed to HIV-related stigma. Intersecting identities such as immigrant status, race/ethnicity, and having a non-English language preference, all intermingle to further influence access to the U.S. healthcare system, including for HIV testing. These findings can be used to inform future research on community-led approaches to addressing early HIV testing amongst African immigrant communities.
\end{abstract}

Keywords HIV $\cdot$ HIV testing $\cdot$ African immigrants $\cdot$ HIV-related stigma $\cdot$ Intersectional stigma

\footnotetext{
Nahom Daniel and Shukri Hassan: Co-first authors.

Roxanne P. Kerani and Rena C. Patel: Senior co-authors.

Rena C. Patel

rcpatel@uw.edu

Department of Biology, UW, Seattle, WA, USA

2 Department of Medicine, UW, 325 9th Ave, Seattle, WA 98105, USA

3 Somali Health Board, Tukwila, WA, USA

4 Department of Global Health, UW, Seattle, WA, USA

5 Department of Anthropology, UW, Seattle, WA, USA

6 Ethiopian Community in Seattle, Seattle, WA, USA

7 Ethiopian Health Board, Seattle, WA, USA

8 Eritrean Health Board, Seattle, WA, USA
} 


\section{Resumen}

Los inmigrantes africanos son afectados por el VIH de manera desproporcionada en comparación con individuos nacidos en E.E.U.U. y el testeo temprano de VIH es el desafío clave para parar la epidemia de VIH en estas comunidades. El estigma relacionado con el VIH parecería ser la barrera más importante al testeo temprano de VIH entre las comunidades africanas en el condado de King, Washington. En este estudio formativo hemos realizado treinta entrevistas con informantes clave y cinco grupos de discusión ( $\mathrm{n}=72$ participantes totales) con participantes etíopes, somalíes, y eritreos viviendo con el VIH, profesionales de la salud, líderes religiosos y de la comunidad, y otros miembros de la comunidad en el condado King para desarrollar un mejor conocimiento de los estigmas interseccionales y relacionados con el VIH. Usamos métodos de codificación inductiva y análisis temático. Participantes de todas las comunidades reportaron temas similares al describir como los estigmas interseccionales y relacionados con el VIH influyen en los comportamientos de acceso a pruebas de VIH. Malentendidos o mensajes inadecuados, por ejemplo, sobre la tratabilidad del VIH y las creencias normativas o religiosas/ morales entorno al sexo pre/extramarital, contribuyeron al estigma relacionado con el VIH. Las identidades que se intersecan, como el estatus migratorio, raza/etnia, y no hablar inglés como lenguaje preferido, se entremezclan para influir de mayor manera el acceso al sistema de salud estadounidense, incluyendo para las pruebas de VIH. Estos hallazgos pueden ser usados para informar futuros proyectos de investigación sobre estrategias lideradas por la comunidad para abordar el diagnóstico temprano de VIH en la comunidad de inmigrantes africanos.

\section{Introduction}

In 2019, the U.S. government and partners announced the initiative for Ending the HIV Epidemic: A Plan for America (EHE), a vision to use four key pillars - diagnose, treat, prevent, and respond - to reduce incident HIV in the U.S. by at least $90 \%$ by 2030 [1]. King County, WA, where the city of Seattle is located, is among 48 priority counties and two cities which accounted for over $50 \%$ of HIV diagnoses in the U.S. in 2016-2017 [2], and is therefore considered a priority jurisdiction for EHE funding and activities. King County, WA and several other EHE jurisdictions include large African immigrant populations, which are disproportionately affected by HIV. For instance, African immigrants account for $2 \%$ of the King County population but $10 \%$ of the new HIV diagnoses [3-5]. Overall, African immigrants represent a small but growing share of the American population, increasing 251\% from 2000 to 2016 [6]. Members of African immigrant communities are more likely to have a late diagnosis than U.S.-born people throughout the U.S., including in King County, WA [7-9]. The HIV diagnosis rate among African immigrants in King County was fivefold that of the overall population (50 vs. 10 per 100,000 population) in 2018, multiple folds higher in African immigrants than U.S.-born Blacks, including men who have sex with men (MSM) [8]. We see that while late HIV diagnosis is common among African immigrants in King County, these communities tend to do as well or better than their U.S.born counterparts in later stages of the HIV care continuum [8-10].

Therefore, the key barrier to ending the HIV epidemic for African immigrant communities is early testing, or Pillar 1 (Diagnosis) of the EHE plan. While a spectrum of individual, interpersonal, organizational, and structural barriers and facilitators exist for HIV testing among immigrant communities, stigma around HIV is a key, and often the leading, barrier identified among African immigrants [11, 12]. HIV transmission in African immigrant communities tends to be largely via heterosexual routes, with both incident local acquisitions and infections acquired in the countries of origin [13]. Thus, experiences around HIV, including HIV testing and stigma, are different for African immigrant communities than, for example, white or even Black MSM born in the U.S.

In our prior work in Harambee! 1.0 we offered free, community-based and integrated HIV testing with other preventative health services among three of the largest African immigrant communities in King County, namely the Ethiopian, Somali, and Eritrean communities [11]. Our qualitative findings identified HIV-related stigma as the largest barrier to getting tested for HIV among members of these communities. To further explore exactly how HIV-related and intersectional stigmas impact HIV testing behaviors, we conducted this formative research via qualitative methods. We also aimed to elicit community feedback on potential stigma reduction interventions to help improve uptake of early HIV testing.

\section{Methods}

\section{Study Setting, Academic-Community Partnership, and Positionality}

This research took place as part of an academic-community partnership, between the University of Washington (UW) researchers and the Ethiopian, Somali, and Eritrean health organizations and their leaders. This partnership arose from our ongoing work in addressing barriers to HIV testing amongst African immigrant communities in King County, 
WA. This partnership utilized principles of communitybased participatory research (CBPR) [14, 15]. Specifically, we prioritized principles of equity (e.g., equitable distribution of financial resources), justice (e.g., representation of community partners in all steps of the research process), and sustainability (e.g., bidirectional capacity-building and commitment to organizational priorities) in this partnership. For an effective partnership, we incorporated practices of cultural humility, trust, a history of partnerships, shared decision-making, capacity-building, bi-directional learning, and a regular process of reflection on project progress at the partnership level. Community members were valued as equal contributors, and often leaders, to the conceptualization and implementation of study design, data analysis and interpretation of findings, intervention selection, and dissemination of findings to both scientific and community audiences. Nearly half of our study budget went directly to our community partners to support them as active members of the research team as they contributed to every step of this process. The project team, which included the academic researchers (the three primary investigators did not belong to African immigrant communities, though two belonged to South Asian immigrant communities), study staff (all members belonged to African immigrant communities, including undergraduate research assistants except for one who belonged to a Latinx immigrant community), and community partners (all belonged to the African immigrant communities) met regularly during project planning, implementation, analysis, and dissemination.

\section{Data Collection}

\section{Overall Approach}

Our overall qualitative data approach utilized both key informant interviews (KIIs) and focus group discussions (FGDs). We first conducted the KIIs so as to allow preliminary analyses to inform our discussion guides for the later FGDs. The KIIs were conducted from October 2019 through January 2020 and the FGDs were conducted from March through April 2020 in King County, WA. The KIIs, which took place prior to the COVID-19 pandemic, were conducted in-person and the FGDs, which occurred during the pandemic, were conducted entirely virtually.

\section{Sampling}

We utilized purposive sampling to identify categories of key informants to interview or participants to include in the focus groups, and our community partners determined which participants to recruit and the manner of recruitment. For the KIIs, we sought to sample persons living with HIV (PLWH), healthcare professionals, and religious leaders belonging to
East African immigrant communities. PLWH participants, who we thought could speak amply to their lived experiences with HIV stigma, were recruited from provider referrals from the UW-affiliated county hospital's HIV clinic or case management organizations. Since our KII data indicated a strong preference to include religious leaders and institutions in any HIV-related stigma intervention, in our FGDs, we heavily sampled religious leaders, though we also included other community leaders as well as some lay community members. For the FGDs, we did not attempt to knowingly recruit any PLWH, to avoid any potential inadvertent disclosure or traumatizing conversations. An informed consent form was provided in all relevant languages (see below), and participants provided oral consent. Patient demographics (age, gender, country of birth, occupation, and religious affiliation) were collected from each participant prior to the KIIs or FGDs. Each participant was provided $\$ 50$ cash reimbursement for either the KII or FGD participation. Saturation of themes within categories of participants guided our sampling numbers.

\section{Interviewers and Facilitators}

Our community partners selected the interviewers and facilitators from their respective communities. Interviewers/ facilitators were first generation Americans and were bi- or trilingual, speaking at least two of the following languages: English, Amharic, Tigrinya, Somali, or Kiswahili. We conducted centralized trainings for interviewers in October 2019 and facilitators in February 2020; some of the interviewers had marked prior experience conducting KIIs or FGDs and all of the facilitators had significant prior experience conducting FGDs. The interviews were conducted to match the interviewer's language with the native-speaking participant whenever feasible. Of note, due to potential disclosure concerns for PLWH participants [16], we offered them options to undergo the interview with project members not belonging to any of the African immigrant communities, and two such participants chose such interviewers; these interviews and consents were conducted in English. For each FGD, the facilitator led the discussion while a second team member belonging to the community served as the note taker. While three of the study team members (RCP, RPK, and FM), joined at the beginning of each FGD to welcome and thank the participants with live translations by the facilitator, the remainder of the FGDs took place in the native language and included only members of each respective community.

\section{Interview/Discussion Procedures}

KIIs were conducted at various locations within the metropolitan Seattle area, such as ethnic community centers or health organization offices, dependent on the preferences of 
the interviewee and interviewer. The FGDs were conducted virtually via Zoom. Interviews and discussions were audio recorded and translated and transcribed directly into English by the same interviewer/facilitator or a second member of the same community partnership team. If the transcriptionist was not the interviewer, the interviewer reviewed the English transcription for accuracy, and any discrepancies were resolved via consensus.

\section{Interview/Discussion Guides}

The KII guide focused on the following five main domains: (1) interactions with the U.S. healthcare system; (2) barriers to health screenings; (3) stigma around health screenings and HIV-related stigma, including for HIV testing; (4) intersectional stigma and influence on HIV testing; and (5) how to reduce stigma around health screenings, including HIV testing. The FGD guide focused on the following three main domains: (1) stigma around health screenings and HIVrelated stigma, including for HIV testing; (2) intersectional stigma and influence on HIV testing; and (3) intervention development for stigma reduction around HIV, with emphasis on the role of religious leaders and institutions. With the goal of providing direction for an intervention choice, during the FGDs, three HIV stigma reduction intervention prototypes, one of which was faith-based, were discussed [17-20]. Of note, when interrogating intersectional stigma, our team was drawn to Earnshaw's Stigma and HIV Disparities Model as a framework for building out probes for our guides [21]. The Stigma and HIV Disparities Model developed by Earnshaw and colleagues describes the concurrent impact of coexisting marginalized identities and explains the negative impact that intersectional stigma has on HIV outcomes. In this model, multiple stigmas interact to affect both structural and individual-level processes. Stigmas may interact through multiple pathways, such as reduced access to health care (a structural-level manifestation of anti-immigrant stigma) and anticipated stigma related to a positive HIV test (the result of HIV-related stigma and/or homonegativity), to negatively impact HIV testing. A second model component pivots around resilience resources at the individual and community levels. However, we did not restrict ourselves to only the Earnshaw model in developing our guides and probes; we also borrowed from Rao et al.'s multilevel stigma model [22] and the socioecological model [23]. The KII and FDG guides can be found in supplementary text.

\section{Data Analysis}

English transcripts were uploaded into NVivo (version 12.0, QRS International Pty Ltd.). We utilized inductive coding, and three team members (SAH, NJ, and GB) with guidance from RCP, RPK, and FM conducted the coding. We developed an initial codebook in a group setting based on the KII and FGD guides and a read of the initial few transcripts, and iteratively adapted the codebook as coding of transcripts progressed. Initial coding was done on the first transcript with all three coders together, then 1-2 transcripts were double-coded individually by coders, and any discrepancies in coding were resolved by consensus. Thereafter, the remaining transcripts were coded individually by separate coders, with one coder (SAH) reviewing the coding for all transcripts. We used thematic analysis [24, 25] through several group meetings, to arrange the codes into three thematic domains with corresponding sub themes, both convergent and divergent, in conjunction with illustrative quotations.

\section{Results}

We conducted a total of thirty KIIs and five FGDs, with one participant from the KIIs also participating in one of the Ethiopian FGDs ( $n=72$ total participants; Table 1). Our Ethiopian and Somali community partners conducted sex-specific FGDs while our Eritrean partner chose to conduct one FGD with participants of both sexes. Out of the 72 total participants, 26 (36\%) were born in Ethiopia, 27 (37\%) in Somalia, 17 (23\%) in Eritrea, and one each were born in Kenya and the U.S. (with the U.S. born individual identifying with the Eritrean community). In total, 35 (48\%) of our participants identified as female. Respondent ages ranged from 22 to 67 years, with over half of participants between 30 and 49 years of age. The majority of participants worked as healthcare professionals $(n=15)$ or as religious leaders $(n=14)$. Five individuals identified as PLWH, all of whom participated in the KIIs.

Overall, in analyzing potential influences on HIV testing behaviors among the Ethiopian, Somali, and Eritrean immigrant communities in the Seattle area, four major themes emerged: (1) culture and stigma, (2) HIV-related stigma, (3) intersectional stigma, and (4) other influences. We present these four themes in detail below, beginning with a broad understanding of culture and stigma in these communities to provide greater context for our later findings. In general, there were far more commonalities across the three communities than differences. So, when differences exist, we highlight them, otherwise the findings are applicable to all three country-of-origin communities queried in this study. Table 2 provides example quotations from the interviews and focus groups, organized by themes described below.

\section{Culture and Stigma}

\section{Social Networks and Cohesion}

Within each country-of-origin community, the overall orientation of the culture towards any stigma played a role in how 
Table 1 Sociodemographic characteristics of study participants

\begin{tabular}{|c|c|c|c|}
\hline & Total participants & $\begin{array}{l}\text { Key informant inter- } \\
\text { views (KIIs) }\end{array}$ & $\begin{array}{l}\text { Focus group } \\
\text { discussions } \\
\text { (FGDs) }\end{array}$ \\
\hline & Number $(\mathrm{n}=72)^{\mathrm{a}}$ & Number $(n=30)$ & Number $(n=43)$ \\
\hline \multicolumn{4}{|l|}{ Age } \\
\hline$<30$ & $5(7 \%)$ & $2(7 \%)$ & $3(7 \%)$ \\
\hline $30-49$ & $48(66 \%)$ & $16(53 \%)$ & $32(74 \%)$ \\
\hline $50+$ & $20(27 \%)$ & $12(40 \%)$ & $8(19 \%)$ \\
\hline \multicolumn{4}{|l|}{ Gender } \\
\hline Male & $38(52 \%)$ & $16(53 \%)$ & $22(51 \%)$ \\
\hline Female & $35(48 \%)$ & $14(47 \%)$ & $21(49 \%)$ \\
\hline \multicolumn{4}{|l|}{ Country of birth } \\
\hline Ethiopia & $27(37 \%)$ & $11(37 \%)$ & $16(37 \%)$ \\
\hline Eritrea & $17(23 \%)$ & $8(27 \%)$ & $9(21 \%)$ \\
\hline Somalia & $27(37 \%)$ & $9(30 \%)$ & $18(42 \%)$ \\
\hline Kenya & $1(1 \%)$ & $1(3 \%)$ & 0 \\
\hline U.S. & $1(1 \%)$ & $1(3 \%)$ & 0 \\
\hline \multicolumn{4}{|l|}{ Language of interview } \\
\hline Amharic & $25(34 \%)$ & $9(30 \%)$ & $16(37 \%)$ \\
\hline Somali & $27(37 \%)$ & $9(30 \%)$ & $18(42 \%)$ \\
\hline Tigrinya & $18(25 \%)$ & $9(30 \%)$ & $9(21 \%)$ \\
\hline English & $2(3 \%)$ & $2(7 \%)$ & 0 \\
\hline Kiswahili & $1(1 \%)$ & $1(3 \%)$ & 0 \\
\hline \multicolumn{4}{|l|}{ Occupation } \\
\hline Healthcare professional & $15(21 \%)$ & $8(27 \%)$ & $7(16 \%)$ \\
\hline Religious leader & $14(19 \%)$ & $4(13 \%)$ & $10(23 \%)$ \\
\hline Business/management & $11(15 \%)$ & $5(17 \%)$ & $6(14 \%)$ \\
\hline Education/student & $10(14 \%)$ & $5(17)$ & $512 \%)$ \\
\hline Homemaker & $6(8 \%)$ & $1(3 \%)$ & $5(12 \%)$ \\
\hline Laborer & $3(4 \%)$ & $1(3 \%)$ & $2(5 \%)$ \\
\hline Not working & $3(4 \%)$ & $2(7 \%)$ & $1(2 \%)$ \\
\hline Other community leader & $2(3 \%)$ & $2(7 \%)$ & 0 \\
\hline Other & $9(12 \%)$ & $2(7 \%)$ & $7(15 \%)$ \\
\hline \multicolumn{4}{|l|}{ Community } \\
\hline Ethiopian & $27(37 \%)$ & $11(37 \%)$ & $16(37 \%)$ \\
\hline Eritrean & $18(25 \%)$ & $9(30 \%)$ & $9(21 \%)$ \\
\hline Somali & $27(37 \%)$ & $9(30 \%)$ & $18(42 \%)$ \\
\hline Kenyan & $1(1 \%)$ & $1(3 \%)$ & 0 \\
\hline \multicolumn{4}{|l|}{ PLWH } \\
\hline Yes & $5(7 \%)$ & $5(17 \%)$ & N/A \\
\hline No & $25(34 \%)$ & $25(83 \%)$ & N/A \\
\hline \multicolumn{4}{|l|}{ Religious affiliation } \\
\hline Orthodox Christian & $12(16 \%)$ & N/A & $12(28 \%)$ \\
\hline Evangelical Christian & $9(12 \%)$ & N/A & $9(21 \%)$ \\
\hline Islam & $20(27 \%)$ & N/A & $20(47 \%)$ \\
\hline Catholic & $1(1 \%)$ & N/A & $1(2 \%)$ \\
\hline Protestant & $1(1 \%)$ & N/A & $1(2) \%$ \\
\hline
\end{tabular}

${ }^{a}$ One individual from the Ethiopian community participated in both a KII and a FGD 
Table 2 Main themes, subthemes, and example quotes for factors influencing HIV testing behaviors among Ethiopian, Somali, and Eritrean immigrant communities in King County, WA

\begin{tabular}{|c|c|c|}
\hline Main theme & Subtheme & Example quotes \\
\hline Culture and stigma & Stigma, social cohesion, and networks & $\begin{array}{l}\text { "Your father, mother and your siblings won't like it. So instead } \\
\text { of focusing on the sickness and try to take care and encourage } \\
\text { them and give them hope, they get very upset by the sickness } \\
\text { and blame the person saying, "You've let us down so people } \\
\text { will talk about us because you were careless." Hence, it leads } \\
\text { to fights, quarrels and blame. They won't think about solu- } \\
\text { tions. Therefore, the person doesn't want to go to their family } \\
\text { for they don't want the fights or quarrels so they distance } \\
\text { themselves from their family and they blame themselves." } \\
\text { (Eritrean FGD 1) } \\
\text { "When we speak about stigma, I mainly think of putting some- } \\
\text { one else down. Thinking you are less than others and seeing } \\
\text { yourself as not being whole as a person, and that you are less } \\
\text { whole than your family members or community. If you do not } \\
\text { consider yourself as a whole person instead of speaking and } \\
\text { interacting with others, you may choose to be separated from } \\
\text { others. Another thing you may also have the perception that } \\
\text { people are gossiping about you or spreading rumors about } \\
\text { you." (Eritrean FGD 1) } \\
\text { "It's basically shaming and it's all over the community. For } \\
\text { example, if a girl would become pregnant outside of wedlock } \\
\text { for whatever reason, everyone in the community will dis- } \\
\text { criminate and stigmatize against that girl even including her } \\
\text { own family at times. And it happens a lot. Everyone seems as } \\
\text { if the whole community says oh that person or so and so has } \\
\text { this and that so nobody should go near them or even speak to } \\
\text { them" (Somali FGD 2) }\end{array}$ \\
\hline
\end{tabular}


Table 2 (continued)

\begin{tabular}{lll}
\hline Main theme Subtheme & Example quotes
\end{tabular}

Stigma around many health conditions

HIV-related stigma
Misconceptions around treatability of HIV
"If I back up for a minute to when I was talking about stigma against mental health or cancer or HIV and AIDS, we've also seen people turn other non-serious health conditions like diabetes into a stigma. For example, internally within the community, this talks of so and so family has the best girls to be married from. So, for example, if someone in that family either the father or the son or the daughter has diabetes, now people talk about them to other people who might want to marry them, not to marry from them because of that diabetes is within the family's gene. We've seen that. People are told to think twice before they marry someone from that family. That also is another form of stigma. So that is what I wanted to back it up to shed some light on this also that type of stigma in the community" (42-year-old female, Somali, health coach/interpreter)

"There is major denial in our community when it comes to mental illness. Even some parents with children who suffer from mental illness, they would prefer to take their children to church and receive traditional medicine (holy water) instead of seeking medical treatment. Families tend to hide mental illness in fear of being cast out for their community." (Ethiopian FGD 1)

"And the other one is the misconception within the community or society to stigmatize or to even bedevil a non-contagious or not serious illness or deformity due to misunderstanding. Or, two, take a very manageable situation out of proportion due to his understanding or ignorance. For example, within our community families whose children might have a certain disability or might be on a certain spectrum that would benefit from something like a speech therapy, that family might be very reluctant or even avoid altogether seeking that help due to fear of being seen within the community as a family with a sick child, and due to fear of stigmatization within the community. And as a result, the child may not get the help and resources he or she needed due to that stigma associated with any health problem that's misunderstood within the community." (Somali FGD 1)

"What I also think is necessary is educating people about treatment and availability of medication. Explaining to people that there are many medications available to keep people alive for a long time is so crucial. In our community people believe that individuals who contract HIV virus will not survive, therefore do not need medical care. Providing awareness about life expectancy of HIV positive individuals, advancement of medication, and treatments will help encourage people to get screened and ease their minds. We must communicate with them that each of us has the responsibility to take care of each other and an obligation to reduce transmission of this disease." (Ethiopian FGD 1) 
Table 2 (continued)

\begin{tabular}{ll}
\hline Main theme & Subtheme \\
\hline & Misconceptions around transmissibility of HIV
\end{tabular}

Example quotes

Misconceptions around transmissibility of HIV

Association of HIV with other stigmatizing behaviors

Association of HIV with religious/moral beliefs

Intersectional stigma

Immigration/refugee status
"For example, people who have HIV and AIDS are isolated or segregated and the main reason for that is people think that if they touched that person or come into contact with them that they will get the disease. Let's mean cause, because the community does not understand what causes it and how it spreads. So, people are avoided because of the perception that any person or anywhere they touch they can contract the disease, and that is ignorance within the society. And that is something that's needed to be used to create widespread awareness within the community." (Somali FGD 1)

"The first one is about sex, we assume, at least in my experience, when people hear HIV they associate it with sex, which is not always true but that is how we are wired. The other one is the perception, if you are HIV your life is over. This kind of perception makes it harder to accept if they happen to have HIV and be accepted by the community as a normal person, as a normal human being that happens to have HIV." (22-year-old male, Eritrean, student)

"The fact that HIV transmits through multiple and unprotected sexual contact has compelled us to see the virus as a monster. Within our context, that is the Ethiopian community, it is a taboo. It is hard. It is shameful and disgusting" (45-year-old female, Ethiopian, unemployed)

"Homosexuality is a major issue in the community so there is no doubt that they would be stigmatized. If someone is homosexual, they would never risk to be recognized so they would never do HIV screening." (62-year-old male, Eritrean, manager)

"Yeah with faith there's some people, they even say it is a curse. They say this is a devil disease, this is a curse". (38-year-old, Kenyan, banker)

"And, in Kenya where I lived as a refugee, people would often talk about HIV and AIDS. And anyone who was suspected of it would be talked about all over the camp. They would often speak about that person as if they are cursed or have some sort of a God's wrath over them so it won't be easy for them to interact with people in the society or the people in the site would not be willing to have anything to do with them." (38-year-old male, Somali, student)

"Especially these days being an immigrant is difficult. For some, an immigrant is just garbage that does not add any value to the society and the country and only brings bad things. On top of this, if you bring in the HIV factor that would be another thing. So, it certainly creates intersectional stigma. The immigrant factor I believe has worsened in recent years with the current administration. The dynamics has changed. If you talk in another luggage that is one stigma and if you add HIV on it that is a whole other thing. There is an open dislike for immigrants these days." (34-year-old female, Ethiopian, nurse) 
Table 2 (continued)

\begin{tabular}{ll} 
Main theme & Subtheme \\
\hline Race/ethnicity
\end{tabular}

Race/ethnicity

Non-English preference

Other intersecting identities
Example quotes

"Being black or being an immigrant can be a stigma. Sometimes just because you are an immigrant some people assume you are dumb or illiterate. I think these are among the stigmas our community sometimes face. Some people equate hunger and Ethiopia and that also creates stigma. And sometimes being black is equated with being lazy and as an immigrant you are just here to use the opportunities the country provides without adding any value." (34-year-old female, Ethiopian, nurse)

"I think it is something that prevents a lot of people from accessing health care in the way that they would want to. There are huge cultural issues. There's a huge intimidation accessing a space when people don't look like you or don't speak your language and you are a burden. So, there is a lot of that, that continues until today and with each community, they face unique challenges and the system like I said still has institutionalized and structural racism. Which makes it difficult for people who have intersectional identities to access." (32-year-old female, Somali, doctor)

"When someone from our community goes to the hospital instead of getting the same treatment, sometimes it's possible that they're told since you've been through a lot more difficult situations; you don't need to be treated for so and so illness. Because you're already prejudged by how you look or what language you speak or do not speak" (Somali FGD 1)

"Even though these diseases exist wherever you go in the world, when you come to United States as an immigrant, if you don't have anyone who supports you, if you have language barrier, it can cause mental distress among many people. What people expect America offers when they come into this country and what they experience (the reality) is very different. That causes a mental health issues, isolation, and other problems. I think these issues need to be addressed before we even start talking about HIV screening." (Ethiopian FGD 1)

"I think that if I'm going to be $100 \%$ honest, I think that if that person is a minority of any sort, I almost guarantee that they're probably going to be looked at in a different light. I think it's different if you have HIV and you're black. I think it's different if you have HIV and you're an immigrant, or you know, a drug user. Or a sex worker. I think all those things that have extra discrimination and that's like two strikes against the patient. And whether it happens explicitly or implicitly, there is bias that goes into a doctor patient relationship." (32-year-old female, Somali, doctor)

"I think the issue of homosexuality is linked with culture. Homosexuality in our community and culture is considered to be abhorrent. If one is a homosexual and then HIV positive, then that is like a double sword. So, it is very hard for the community to accept these individuals and this might discourage testing. In regards to mental illness, I think it is better than homosexuality in our community. Because mental illness is a disease so it is not seen as homosexuality." (58-year-old male, Ethiopian, pastor) 
Table 2 (continued)

\begin{tabular}{ll}
\hline Main theme & Subtheme \\
\hline $\begin{array}{c}\text { Other factors influ- } \\
\text { encing HIV testing } \\
\text { behaviors }\end{array}$ & Immigration statu
\end{tabular}

Racism, including structural racism

Non-English preference and use of interpreters Example quotes

"...we're being brought to the U.S. from Nairobi for example, when someone is found to have HIV and AIDS during the medical tests, they might be told to take treatment or be denied the opportunity to be settled here" (63-year-old male, Somali, educator)

"Yes, it truly affects me since I am not educated, have a language barrier and that I am an immigrant with HIV, I fear I may not get my citizenship accepted." (31-year-old female, Eritrean, case manager)

"Another thing, since everyone who is entering America get screened prior to coming here, they do not bother getting tested once they are here. They are convinced they do not have it, but like we talked about it earlier, for example using faith-based organizations would be one way to educate members." (Ethiopian FGD 2)

"And even when speaking on HIV and AIDS specifically the impact that it has on the respective communities is very different due to institutional racism and racism itself. Institutional racism manifests as different patients from different backgrounds receiving different tests and treatments. For example, they might say that so and so is from Africa and should only get so and so tests done compared to the other patient who is from here, for example. Even though many amazing doctors are out there, unfortunately for most doctors their perceptions on how they were raised trumps over their trainings in medicine and ethics." (Somali FGD 1)

"Some people might be afraid of being discriminated. I don't know. I am sure there is more discrimination because of our color. If we compare two HIV patients (white and black), even though their diagnosis is the same, I am sure the person of color will be afraid of being discriminated. I think that's just based on history." (ETH FGD 1)

"When I was a medical interpreter, I was at a hospital for interpretation for this lady in our community who had double mastectomy. I sensed that she was very uncomfortable because I was from the community." (34-year-old female, Ethiopian, nurse)

"Some people don't feel comfortable using interpreters. They want their health situation kept confidential and sharing that to another community member is something they don't feel comfortable doing most of the time. Our culture also contributes a lot here. There is a trust issue when it comes to sensitive health information. (54-year-old male, Ethiopian, retired) 
Table 2 (continued)

\begin{tabular}{|c|c|c|}
\hline Main theme & Subtheme & Example quotes \\
\hline & Gender/sex differences & $\begin{array}{l}\text { "Yes, there is a difference. In general, men have self-negli- } \\
\text { gence. We don't take care of ourselves until we're broken. } \\
\text { Women are more conscious about their well-being due to } \\
\text { fertility and pregnancy conditions. They need to do specific } \\
\text { screenings from early age so they tend to be better aware for } \\
\text { their health than their male counterpart. Women are naturally } \\
\text { more self-aware."(50-year-old male, Eritrean, nurse) } \\
\text { "As far as stigma is concerned, a lot of Habesha men, from my } \\
\text { experience, do not go to the hospital. Men associate getting } \\
\text { tested with being vulnerable and exposing their sexual behav- } \\
\text { iors. They believe if they don't get tested, they would not find } \\
\text { out they have a disease. I think that is one of the major issues } \\
\text { in our community. This is due to lack of knowledge. We } \\
\text { wait until we get sick to go to a doctor. The older generation } \\
\text { believes that it will be best not to know or find out they may } \\
\text { be HIV positive if they are a certain age because they fear } \\
\text { being ostracized from their community." (Ethiopian FGD 1) } \\
\text { "Men associate getting tested with being vulnerable and } \\
\text { exposing their sexual behaviors, and women lack the power } \\
\text { to make healthcare decisions, and do not get tested in fear } \\
\text { of losing their family and not ever getting married again" } \\
\text { (Ethiopian FGD 1) }\end{array}$ \\
\hline
\end{tabular}

Difficulties navigating U.S. healthcare systems

"I think from my understanding from this question, more than anything having health insurance affects people more when it comes to treatment. People do not understand the coverage of their insurance, or if screening is free or covered by their health insurance. I think that will affect the immigrant community more than just their status. I don't believe being an immigrant make people more vulnerable to contract HIV, but the fear or not understanding the healthcare system affects how people respond when they have the disease or even to the initial screening." (Ethiopian FGD 1)

"The people who were born here, they are more likely to get screened whereas those who came here as immigrants with different cultures, they are more likely not to be screened. And the reason for that is the countries that these immigrants are originally from, usually health care and hospital in general are a few and rare." (38-year-old male, Somali, student)

"We do not know the system as much as those who are from America. It is a knowledge gap between both groups. First of all, one has to convince himself to get screened and get services like case management and language interpretation services. It needs confidence and trust with case managers and to develop courage and confidence, even when you are not educated." (31-year-old female, Eritrean, case manager)

stigma around HIV manifests, including for HIV testing. Participants routinely mentioned that the concept of stigma was tied to beliefs of shame and isolation. Importantly, these beliefs around stigma have implications not only for the individuals but went on to have marked ramifications for their extended families or tribes/clans. Therefore, there was a large emphasis on stigma affecting social cohesion of whole networks of communities. Relatedly, participants also described using secrecy to maintain social cohesion amongst their social networks, in order to maintain strong relations between themselves and their community.

\section{Stigma Around Other Health Conditions}

Multiple health-related stigmas existed, and the stigmatization of health conditions often related to cultural norms around remembering those who have died of that illness, instead of focusing on those living with it. Identifying those 
living with such conditions is also more challenging given that community members often do not disclose the health conditions they may be living with due to perceived stigma. Communicable diseases such as tuberculosis and COVID19 , along with non-communicable diseases such as diabetes, hypertension, mental health, and cancer, were all mentioned as stigmatized health conditions within these communities. Several participants mentioned how after they disclosed a disease diagnosis, members of their community would list, more often than not, others who passed away from it. Nonetheless, despite there being stigma around most health conditions, it appears that a hierarchy for stigma, and conversely empathy, exists, with HIV being the most stigmatizing condition among the rest. For example, although participants noted that cancer is stigmatized in their communities, they also highlighted how their communities empathize more with those with cancer than those with HIV.

\section{HIV-Related Stigma}

Participants from each country-of-origin community consistently noted that HIV-related stigma was the leading influencer of HIV testing behaviors, and that HIV is a heavily stigmatized disease, often to the point that HIV is rarely even mentioned or discussed in their communities. Four main subthemes or drivers of HIV-related stigma emerged: (1) the diagnosis of HIV being a death sentence or treatability of HIV; (2) misconceptions or poor messaging around the transmissibility of HIV; (3) normative beliefs around HIV and other stigmatizing behaviors such as pre/extramarital sex; and (4) the religious belief that HIV is a punishment for such behaviors. We explore these subthemes below.

First, HIV is a heavily stigmatized condition because many community members still consider an HIV diagnosis as a condition rapidly leading to death. Participants perceived a general lack of awareness within their communities when it comes to surviving and living positively with HIV. Interestingly, a normative element existed to this belief as many participants themselves acknowledged that, with treatment, PLWH can have a "normal" lifespan. However, participants felt strongly that most community members did not know enough about HIV prevention, different modes of HIV transmission, or HIV treatment and noted that lack of culturally-appropriate information provided by their community members fuels misconceptions. Furthermore, participants noted that any misbeliefs or misinformation was further worsened by community members not personally knowing anyone living with HIV who belongs to their community.

Second, one specific belief about HIV which influences HIV testing behaviors was driven by misconceptions over "contagion" or "contagiousness" of HIV. Fear of contracting the disease via casual contact drove community members, participants thought, to wanting to physically and socially distance themselves from individuals living with HIV. Subsequently, such fear, based in misinformation, leads to social isolation of PLWH and, in turn, creates an additional negative social consequence for otherwise socially cohesive communities.

Third, HIV acquisition is associated with other highly stigmatized behaviors within these communities, and of such behaviors, pre/extramarital sex (generally in the context of cisgender sex) was one identified most commonly. Given the importance of religion in these communities, and because pre/extramarital sex is considered a sin, such behaviors are highly stigmatized. Simultaneously, pre/extramarital sex emerged as the most commonly mentioned mode of HIV transmission in these communities. Thus, a diagnosis of HIV was associated with pre/extramarital sex, compounding the stigma around both. Other stigmatizing behaviors, such as men having sex with men, intravenous drug use, or transactional sex were mentioned at times as being associated with HIV, and therefore, further contributing to HIV-related stigma, including for HIV testing. One participant in a FGD worried that PLWH might even internalize these judgements on morality and perpetuate self-stigma and self-isolation, though this concern was not directly voiced in the KIIs with any of the PLWH. The commonality amongst these behaviors were perceptions of immorality associated with these behaviors in the communities.

Fourth, in light of the above association of HIV with other highly stigmatizing behaviors, stigma around HIV was driven by strong overall religious or spiritual implications of living with HIV. For example, some participants reported community beliefs that PLWH were being punished for their immoral behaviors by God or being tested by God. Others reported community beliefs around PLWH having a curse from God or spirits.

\section{Intersectional Identities and Stigma}

As suggested above, our analysis identified intersectional stigma, a separate factor from HIV-related stigma, as an important influence on HIV testing behaviors amongst these communities. Intersectional stigma was especially important as it relates to interacting with the U.S. healthcare system more generally. Stigmas across health conditions and intersecting identities such as immigrant status, race/ethnicity, non-English language preference, gender/sex, and being from a religious minority all tie into how these communities can access and benefit from the U.S. healthcare system. Several participants mentioned that they believe their immigrant/refugee status is perceived as a burden to the general U.S. society, and many members of their communities do not feel entitled to receive healthcare services in the U.S. For example, one participant mentioned if they were to accept any benefits or care from the U.S. government, it will be 
seen as a burden and may negatively affect their immigration case. Another participant worried that the combined stigmas of being an immigrant and a PLWH could influence rejection of their citizenship request. Another barrier in accessing and benefiting from the U.S. healthcare system is institutionalized racism. Participants from each countryof-origin community relayed their experiences in differential treatment in healthcare settings based on their race and what language they spoke. One participant in particular noted the negative stereotypes perpetuated by U.S. society prevalent in healthcare settings, such as being Black equated to being lazy, being from an African country equated to being hungry, and being an immigrant with a non-English language preference equated to being illiterate. Additionally, having a non-English language preference makes it difficult for an individual to communicate directly with their provider and requires the use of an interpreter. The use of an interpreter, in turn, discourages HIV testing because the individual might fear stigmatization or feel uncomfortable addressing private information with an interpreter present, who is likely a member of their community. These barriers have very significant implications for all aspects of interacting with healthcare systems, with specific implications for seeking HIV testing.

\section{Other Factors Aside from Stigma that Influence HIV Testing Behaviors}

Our analysis revealed that many of the intersecting identities directly, and independently of any stigma, influence HIV testing behaviors and uptake of preventative healthcare more generally. For example, immigration status, non-English language preference, gender differences, and navigating the US healthcare system all directly influence HIV testing behaviors outside of the role they may play in intersectional stigma within these communities. For immigration status, for instance, participants mentioned a fear of testing positive for HIV would negatively influence their immigration or residency status. Thus, staying away from HIV testing would best protect their ability to stay in the U.S. Another unique element, related to immigration, was the idea of prioritizing working and the ability to provide for families over perceptions of self-care. Furthermore, some identified a notion of "survivorship," having survived war-torn environments, displacement or refugee camps, or lengthy immigration procedures, creating momentum to keep prioritizing provision for family over seeking HIV testing. Having a non-English language preference is a barrier they mentioned in regards to trying to utilize the U.S. healthcare system, because not being able to freely converse with a provider limits rapport, along with appointment times being shortened due to use of interpretation services. Additionally, the use of interpreters can lead to issues with anonymity, confidentiality, and inaccurate translations, and such concerns can influence HIV testing because of fears of stigma and isolation in these otherwise socially cohesive communities. Gender differences were also noted as a barrier to HIV testing in some communities. Women are perceived to have greater access to routine testing, particularly during their pregnancy care, and seeking HIV testing may better conform to their gendered care-taking roles. Masculinity norms for men, on the other hand, interfered with HIV test-seeking behaviors, particularly because self-reliance is prioritized and illness is seen as a weakness for men in these communities. Lastly, navigating the U.S. healthcare system was mentioned as a barrier, including when testing for HIV, with marked confusion around and challenges navigating insurance policies and coverage plans. Even so, these particular issues pertain to individuals who have health insurance, and some participants mentioned that obtaining insurance coverage itself is either too expensive or difficult to navigate in the first place.

\section{Discussion}

Our study has identified several dominant themes, based primarily upon cultural factors and HIV-related and intersectional stigmas, as influencing HIV testing behaviors among the Ethiopian, Somali, and Eritrean immigrant communities in King County, WA. Additional key insights from our analysis include the effect of stigma on the social cohesiveness of these communities, HIV's unique stigmatization within a larger cultural context of stigmatization of health conditions, and how many of the community members' intersecting identities also have direct influences on HIV test-seeking and other preventative healthcare behaviors. Collectively, these influences foster normative beliefs amongst these communities that often prevent members from seeking or undergoing HIV testing. As we have noted before, the key barrier in ending the HIV epidemic for African immigrant communities in the U.S. is early HIV testing. Thus, addressing HIV-related and intersectional stigmas should be of utmost importance to programs, public health jurisdictions, and communities attempting to end the HIV epidemic amongst African immigrant communities.

Conversations for HIV-related stigma, which invariably involve communities marginalized by minority race/ethnicity, sexual orientation, or immigration status, must shift to include an equity focus, and broadening the conversation to intersectional stigma facilitates that shift. We, as well as others, have shown that barriers to HIV testing among African immigrants include reduced access to health care, HIVrelated stigma, and perceptions of low HIV risk [11, 26-29]. Generalized HIV stigma has been found to be related to lower levels of HIV testing uptake in several populations [30-32]. Combined with HIV-related stigma, intersectional stigmas resulting from having multiple identities devalued 
by society, including being black, immigrants, having a nonEnglish language preference, and, in many cases poor or being a member of a religious minority, may also contribute to low uptake of HIV testing [31, 33-35]. For MSM in this population, being a member of a sexual minority may further contribute to internalized stigma [36, 37]. Intersectional stigma may interact through multiple pathways to negatively impact HIV prevention and care outcomes. The Earnshaw model of Stigma and HIV Disparities incorporates intersectional stigma and resonates with our findings, and in our future work we will be further adapting this model for East African immigrant communities. However, we note that this is not the only model to address intersectional stigma in the context of HIV prevention or care.

HIV stigma-related interventions also need to adapt models for intersectional stigma, with an eye for promoting equity and justice, and interventions that leverage religious identities, leaders, and institutions is a priority among our three African immigrant communities (data not presented here). Several faith-based interventions have been developed or adapted to reduce HIV-related stigma among lay community members, including the FAITH Project [18, 19], Project Fostering AIDS Initiatives that Heal (FAITH) [38], Taking it to the Pews (TIPS) [39, 40], and Project Faith-based Antistigma Initiative Towards Healing HIV/AIDS (FAITHH) $[41,42]$. All of these interventions were developed through community-based participatory research, and address the spiritual beliefs that influence HIV-related stigma in U.S.born African American communities, and as such, they seem like good models for an HIV-related and intersectional stigmas reduction intervention that could be adapted for East African immigrant communities. However, none of these were developed to specifically address intersectional stigma and only one (Project FAITHH) touches on intersectional stigma by including discussion of how poverty and homelessness both contribute to HIV transmission and are both also stigmatized. Based on our findings, in the next phase of our Harambee! work, we plan to adapt Project FAITHH for use in our three partner communities; the adaptation will require changes to incorporate intersectional stigma reduction, as well as changing the materials and activities to better represent Islam alongside Christianity.

Our findings suggest more similarities than differences between the Ethiopian, Somali, and Eritrean communities. Many similarities exist in themes and subthemes, such as how their cultural and religious beliefs add to HIV-related stigma, fear of disease diagnosis, preventative care attitudes, and intersecting identities serving as barriers in navigating the U.S. healthcare system. For example, participants from all three communities acknowledged that their communities socially isolate PLWH in fear of contracting the infection themselves; messaging that is culturally appropriate and led by the African immigrant community members can easily address misconceptions. In addition, adding ways that community members, as peers, can take the role of "health navigator" may also help correct misconceptions, foster trust in the system, and link people to services [43, 44].

Some differences arose when certain themes or subthemes were emphasized more or less in certain communities. For example, gender differences in healthcare-seeking behaviors were more commonly noted in the Ethiopian and Eritrean communities, while lack of trust in interpreters arose more often in the Somali community. Concerns about confidentiality of interpretation services have been documented before $[45,46]$, and our participants and community partners reported known incidents of translators, specifically in the Somali community, having a history of unreliability when it comes to adhering to patient confidentiality rules. Such behaviors further erode trust in the U.S. healthcare system among immigrant communities.

Our work may have several limitations. This work is most readily transferable to other Ethiopian, Somali, and Eritrean communities in the U.S., and may be limited in applicability to other East African or African immigrant communities. However, given the marked similarities and commonalities that arose in our findings, we anticipate many of our findings will resonate with many African or even other immigrant communities in the U.S. [16, 47-49]. The subgroups we chose to prioritize, such as PLWH or religious leaders, may not have captured the breath of various perspectives within each community. Nonetheless, our interviews and focus groups recruited various other types of individuals, so we hope to have captured a sufficiently robust breath of perspectives. Finally, KII participants included somewhat fewer PLWH than we had anticipated recruiting, and the start of the COVID pandemic added complexity to recruitment for in-person interviews. We have previously found that African immigrant PLWH are less likely to agree to participate in research than members of other groups, likely related in part to fears around privacy and confidentiality [50]. Notwithstanding these limitations, our work is the most detailed and involving of the Ethiopian, Somali, and Eritrean communities around HIV-related and intersectional stigmas to date.

\section{Conclusions}

In summary, we have found several themes for how HIVrelated and intersectional stigmas impact HIV testing behaviors among the Ethiopian, Somali, and Eritrean communities in King County, WA, which may be common to other African immigrant communities in the U.S. Amongst these communities, while cultural beliefs contribute to stigma around many health conditions, stigmatization of HIV is unique. Misconceptions or poor messaging appears to contribute to 
HIV-related stigma. While misconceptions might be easily remedied, some of the normative or religious/moral beliefs associated with HIV may prove more challenging to address. Intersecting identities such as immigrant status, race/ethnicity, and having a non-English language preference all interact to further influence access to the U.S. healthcare system, including for HIV testing. Given that intersectional stigmas are considerable barriers for HIV testing among African immigrant communities, future research into communityled approaches of addressing intersectional stigmas is necessary to improve access to care and health outcomes among these communities. Overall, our findings point to the likely usefulness of peer navigators and interventions rooted in community, spirituality, and culture to better link African immigrants with HIV testing services.

Supplementary Information The online version contains supplementary material available at https://doi.org/10.1007/s10461-021-03396-5.

Author Contributions Conceptualization: FM, DR, RPK, RCP, RS, AA, BG. Data curation: RPK, FM, RS, GB, SAH, NS, RCP. Formal analysis: RPK, FM, DR, GB, SAH, NS, NAD, RCP. Interpretation of findings: NAD, SAH, FM, NS, GB, RS, BTG, YKB, LG, KB, BT, HAL, MS, SB, AA, DR, RPK, RCP. Funding acquisition: RPK, DR, RCP. Investigation: RPK, DR, FM, RCP. Methodology: RK, FM, SAH, NAD, DR, RCP. Project administration: FM, SAH, RPK, RCP. Resources: RPK, FM, DR, RS, AA, BG, GB, SAH, NS, NAD, RCP. Software: GB, SAH, NS, RCP. Supervision: RPK, FM, DR, RS, AA, BG, RCP. Validation: RPK, RCP. Visualization: NAD. Writing - original draft: SAH, NAD, RCP, RPK, FM. Writing - review \& editing: NAD, SAH, FM, NS, GB, RS, BTG, YKB, LG, KB, BT, HAL, MS, $\mathrm{SB}, \mathrm{AA}, \mathrm{DR}, \mathrm{RPK}, \mathrm{RCP}$

Funding This study is funded by: National Institute of Allergy and Infectious Diseases P30 AI027757 Recipient: Rena Patel, MD, MPH.

Data Availability Interview and focus group guides are attached in supplemental text. De-identified transcripts may be made available to individual researchers upon request.

Code Availability The codebook associated with this study can be made available to individual researchers upon request.

\section{Declarations}

Conflict of interest The authors have no conflicts of interest to declare that are relevant to the contents of this article.

Consent to Participate Verbal informed consent was obtained from all individual participants prior to each interview and focus group discussion.

Consent to Publish The authors affirm that all participants provided informed consent regarding publishing of their statements.

Ethical Approval This study was performed in line with principles of the Declaration of Helsinki. We obtained ethical approval for study from the University of Washington Human Subjects Division.

\section{References}

1. Fauci AS, Redfield RR, Sigounas G, Weahkee MD, Giroir BP. Ending the HIV epidemic: a plan for the United States. JAMA. 2019;321(9):844-5.

2. Prevention CfDCa. Ending the HIV epidemic: a plan for America, combined HIV diagnoses for 2016-2017, United States. 2019; https://www.cdc.gov/endhiv/diagnoses-2016-2017.html.

3. McHugh M, Morawsk iM. Immigrants and WIOA services: comparison of sociodemographic characteristics of native- and foreign-born adults in King County, Washington. Washington, D.C.: Migration Policy Institute; 2016.

4. Kerani RP, Kent JB, Sides T, et al. HIV among African-born persons in the United States: a hidden epidemic? J Acquir Immune Defic Syndr. 2008;49(1):102-6.

5. HIV/AIDS Epidemiology Unit. Public health - Seattle \& King County and the infectious disease assessment unit. Washington: Washington State Department of Health. HIV/AIDS Epidemiology Report; 2019.

6. Center PR. Facts on immigrants, 20162018.

7. Kerani RP, Satcher Johnson A, Buskin SE, et al. The epidemiology of HIV among people born outside the United States, 2010 2017. Public Health Rep. 2020;135(5):611-20.

8. HIV/AIDS Epidemiology Unit PH-SKCatIDAU, Washington State Department of Health. HIV/AIDS Epidemiology Report 20192019

9. Kerani R, Bennett AB, Golden M, Castillo J, Buskin SE. Foreignborn individuals with HIV in King County, WA: a glimpse of the future of HIV? AIDS Behav. 2018;22(7):2181-8.

10. Erly S, Roberts DA, Kerani R, et al. Assessing HIV Care Outcomes among African-Born People Living with HIV in Seattle: An Analysis of the University of Washington Electronic Medical Record. J Immigr Minor Health. 2020; (in press).

11. Roberts DA, Kerani R, Tsegaselassie S, et al. Harambee!: a pilot mixed methods study of integrated residential HIV testing among African-born individuals in the Seattle area. PLoS ONE. 2019;14(5):6502.

12. Blondell SJ, Kitter B, Griffin MP, Durham J. Barriers and facilitators to HIV testing in migrants in high-income countries: a systematic review. AIDS Behav. 2015;19(11):2012-24.

13. Herbeck JT, Kerani RP, Poon AFY. What proportion of HIVinfected foreign-born individuals in the United States have been infected after immigrating to the United States? J Acquir Immune Defic Syndr. 2018;77(4):e35-6.

14. Belone L, Lucero JE, Duran B, et al. Community-based participatory research conceptual model: community partner consultation and face validity. Qual Health Res. 2016;26(1):117-35.

15 Wallerstein N, Duran B. Community-based participatory research contributions to intervention research: the intersection of science and practice to improve health equity. Am J Public Health. 2010;100(Suppl 1):S40-46.

16. Nevin PE, Frey S, Lipira L, et al. "You are always hiding. It's the worst way to live." Exploring stigma in African immigrants living with HIV in a large Northwest U.S. Metropolitan Area. J Assoc Nurses AIDS Care. 2018;29(3):417-25.

17. Lipira L, Nevin PE, Frey S, et al. The positive living program: development and pilot evaluation of a multimedia behavioral intervention to address HIV-related stigma and depression among African-immigrant people living with HIV in a large, Northwestern U.S. metropolitan area. J Assoc Nurses AIDS Care. 2019;30(2):224-31.

18. Derose KP, Bogart LM, Kanouse DE, et al. An intervention to reduce HIV-related stigma in partnership with African American and Latino churches. AIDS Educ Prev. 2014;26(1):28-42. 
19. Derose KP, Griffin BA, Kanouse DE, et al. Effects of a pilot church-based intervention to reduce HIV stigma and promote HIV testing among African Americans and Latinos. AIDS Behav. 2016;20(8):1692-705.

20. Batey DS, Whitfield S, Mulla M, et al. Adaptation and implementation of an intervention to reduce HIV-related stigma among healthcare workers in the United States: piloting of the FRESH workshop. AIDS Patient Care STDS. 2016;30(11):519-27.

21. Earnshaw VA, Bogart LM, Dovidio JF, Williams DR. Stigma and racial/ethnic HIV disparities: moving toward resilience. Am Psychol. 2013;68(4):225-36.

22. Rao D, Elshafei A, Nguyen M, Hatzenbuehler ML, Frey S, Go VF. A systematic review of multi-level stigma interventions: state of the science and future directions. BMC Med. 2019;17(1):41.

23. McLeroy KR, Bibeau D, Steckler A, Glanz K. An ecological perspective on health promotion programs. Health Educ Q. 1988;15(4):351-77.

24. Braun V, Clarke V. Using thematic analysis in psychology. Qual Res Psychol. 2006;3(2):77-101.

25. Braun V, Clarke V. What can "thematic analysis" offer health and wellbeing researchers? Int J Qual Stud Health Well-being. 2014;9:26152.

26. De Jesus M, Carrete C, Maine C, Nalls P. Attitudes, perceptions and behaviours towards HIV testing among African-American and East African immigrant women in Washington, DC: implications for targeted HIV testing promotion and communication strategies. Sex Transm Infect. 2015;91(8):569-75.

27. De Jesus M, Carrete C, Maine C, Nalls P. "Getting tested is almost like going to the Salem witch trials": discordant discourses between Western public health messages and sociocultural expectations surrounding HIV testing among East African immigrant women. AIDS Care. 2015;27(5):604-11.

28. Ojikutu B, Nnaji C, Sithole J, et al. All black people are not alike: differences in HIV testing patterns, knowledge, and experience of stigma between U.S.-born and non-U.S.-born blacks in Massachusetts. AIDS Patient Care STDS. 2013;27(1):45-54.

29. Mitha K, Yirsalign M, Cherner M, McCutchan A, Langford TD. Risk perception and beliefs regarding HIV infection among Ethiopian immigrants. AIDS Educ Prev. 2009;21(5):484-94.

30. Gamarel KE, Nelson KM, Stephenson R, et al. Anticipated HIV stigma and delays in regular HIV testing behaviors among sexually-active young gay, bisexual, and other men who have sex with men and transgender women. AIDS Behav. 2018;22(2):522-30.

31. Gwadz M, Leonard NR, Honig S, Freeman R, Kutnick A, Ritchie AS. Doing battle with "the monster:" how high-risk heterosexuals experience and successfully manage HIV stigma as a barrier to HIV testing. Int J Equity Health. 2018;17(1):46.

32. Kalichman SC, Simbayi LC. HIV testing attitudes, AIDS stigma, and voluntary HIV counselling and testing in a black township in Cape Town, South Africa. Sex Transm Infect. 2003;79(6):442-7.

33. Morey BN. Mechanisms by which anti-immigrant stigma exacerbates racial/ethnic health disparities. Am J Public Health. 2018;108(4):460-3.

34. Wafula EG, Snipes SA. Barriers to health care access faced by black immigrants in the US: theoretical considerations and recommendations. J Immigr Minor Health. 2014;16(4):689-98.

35. Wyatt GE, Gomez CA, Hamilton AB, Valencia-Garcia D, Gant LM, Graham CE. The intersection of gender and ethnicity in HIV risk, interventions, and prevention: new frontiers for psychology. Am Psychol. 2013;68(4):247-60.

36. Sandfort T, Anyamele C, Dolezal C. Correlates of sexual risk among recent gay and bisexual immigrants from Western and Eastern Africa to the USA. J Urban Health. 2017;94(3):330-8.
37. Shoptaw S, Weiss RE, Munjas B, et al. Homonegativity, substance use, sexual risk behaviors, and HIV status in poor and ethnic men who have sex with men in Los Angeles. J Urban Health. 2009;86(Suppl 1):77-92.

38. Lindley LL, Coleman JD, Gaddist BW, White J. Informing faithbased HIV/AIDS interventions: HIV-related knowledge and stigmatizing attitudes at Project F.A.I.T.H. churches in South Carolina. Public Health Rep. 2010;125(Suppl 1):12-20.

39. Berkley-Patton J, Bowe Thompson C, Goggin K, et al. A religiously-tailored, multilevel intervention in African American churches to increase HIV testing: rationale and design of the taking it to the Pews cluster randomized trial. Contemp Clin Trials. 2019;86:105848.

40. Berkley-Patton J, Bowe-Thompson C, Bradley-Ewing A, et al. Taking it to the pews: a CBPR-guided HIV awareness and screening project with black churches. Aids Educ Prev. 2010;22(3):218-37.

41. Bradley ELP, Sutton MY, Cooks E, et al. Developing FAITHH: methods to develop a faith-based HIV stigma-reduction intervention in the rural south. Health Promot Pract. 2018;19(5):730-40.

42. Payne-Foster P, Bradley ELP, Aduloju-Ajijola N, et al. Testing our FAITHH: HIV stigma and knowledge after a faith-based HIV stigma reduction intervention in the Rural South. AIDS Care. 2018;30(2):232-9.

43 Shommu NS, Ahmed S, Rumana N, Barron GRS, McBrien KA Turin TC. What is the scope of improving immigrant and ethnic minority healthcare using community navigators: a systematic scoping review. Int J Equity Health. 2016;15.

44. Natale-Pereira A, Enard KR, Nevarez L, Jones LA. The role of patient navigators in eliminating health disparities. Cancer-Am Cancer Soc. 2011;117(15):3543-52.

45. Eklof N, Hupli M, Leino-Kilpi H. Factors related to privacy of Somali refugees in health care. Nurs Ethics. 2020;27(2):514-26.

46. Blanchet R, Sanou D, Nana CP, Pauze E, Batal M, Giroux I. Strategies and challenges in recruiting black immigrant mothers for a community-based study on child nutritional health in Ottawa, Canada. J Immigr Minor Healt. 2017;19(2):367-72.

47. De Jesus M, Carrete C, Maine C, Nalls P. Attitudes, perceptions and behaviours towards HIV testing among African-American and East African immigrant women in Washington, DC: implications for targeted HIV testing promotion and communication strategies. Sex Transm Infect. 2015;91(8):569-75.

48. De Jesus M, Carrete C, Maine C, Nalls P. "Getting tested is almost like going to the Salem witch trials": discordant discourses between Western public health messages and sociocultural expectations surrounding HIV testing among East African immigrant women. Aids Care-Psychol Socio-Med Aspects AIDS/HIV. 2015;27(5):604-11.

49. Sabri B. Perspectives on factors related to HIV risk and preventative interventions at multiple levels: a study of African immigrant women survivors of cumulative trauma. AIDS Educ Prev. 2018;30(5):419-33.

50. Kerani R, Narita M, Lipira L, Endeshaw M, Holmes KK, Golden MR. Challenges in recruiting African-born, US-based participants for HIV and tuberculosis research. J Immigr Minor Health. 2019;21(3):533-9.

Publisher's Note Springer Nature remains neutral with regard to jurisdictional claims in published maps and institutional affiliations. 